\title{
Quando um Governo de Esquerda assusta os media - A formação da "geringonça" nos jornais
}

\section{When a Left-wing Government scares the media - The formation of "geringonça" in newspapers}

\author{
Susana Barros*
}

*ISCTE-Instituto Universitário de Lisboa, Portugal

Resumo:

\begin{abstract}
Perante uma tendência interpretativa crescente do jornalismo político em detrimento de um estilo descritivo, os media têm privilegiado a tática face à substância. Longe de ser um mero observador dos acontecimentos, o jornalista assume protagonismo no jogo político, contribuindo quer para o seu desenvolvimento, quer para a construção da perceção publica do mesmo. Incidindo sobre a formação do Governo do PS com o apoio parlamentar do PCP, BE e PEV - conhecido por "Geringonça" -, olhamos para as capas dos jornais Público, Diário de Notícias, Correio de Manhã e Observador, desde as eleições legislativas de 4 de Outubro de 2015 até à aprovação do programa do Governo a 3 de Dezembro de 2015, procurando captar padrões sobre a narrativa jornalística construída acerca de um processo póseleitoral inédito em Portugal. Com um corpus composto por 356 peças (233 capas de jornais e 123 editoriais), neste artigo apontamos para o enquadramento dado a este processo político nas primeiras páginas e para a visão da elite jornalística sobre este período manifestado nos editoriais. Situamos pois este trabalho na área do Agenda-Setting e do Framing na medida em que analisamos a forma como os media apresentam a formação do Governo e as questões que mais salientam durante a negociação política que, no nosso entender, não se podem desligar da maneira como noticiaram os anos de austeridade e a presença da Troika em Portugal. Os resultados mostram que, apesar de derrotado nas urnas, o Secretário-Geral do PS António Costa é a figura principal de um período que é apresentado em torno de dois eixos centrais: Estabilidade (associada à coligação PSD/CDS) / Instabilidade (associada ao PS e à esquerda). Acompanhando a tendência do jornalismo político, é o jogo das negociações e não as políticas em causa que surge destacado pela imprensa cujo discurso dominante chumba a formação de um Governo de Esquerda por motivos económicos e simbólicos.
\end{abstract}

Palavras-chave: Jornalismo político; Agenda-Setting; Framing; Governo de Esquerda; Media e Democracia.

Abstract:

Faced with a growing interpretive tendency of political journalism rather than a descriptive style, the media has favoured tactics over substance. Far from being a mere observer of events, the journalist takes a leading role in the political game, contributing both to its development and to the construction of public perception of it. Focusing on the formation of the Socialist Party Government with the parliamentary support of the PCP (Portuguese Comunist Party), BE (Left Block) and PEV (Green Party) - known as "Geringonça" -, we look at the first pages of the newspapers Público, Diário de Notícias, Correio da Manhã and Observador, since the General Elections of October 4, 2015 until the approval of the Government's program on December 3,2015, trying to capture the patterns about the journalistic narrative about an unprecedented post-election process in Portugal. With a corpus consisting of 356 pieces (233 newspaper covers and 123 editorials), in this article we focus in the framework given to this political process in the first pages and to the view of the journalistic elite about this period revealed in the editorials. We therefore place this work in the area of Agenda-Setting and Framing insofar as we analyze how the media presents the formation of the Government and the issues that most highlight during the political negotiations, which can not be disconnected from the way media had reported the years of austerity and Troika's presence in Portugal. The results show that, although defeated at the election, the Secretary General of PS António Costa is the main figure of a period that is presented around two central axes: Stability (associated with the PSD / CDS coalition) / Instability ( associated with PS and left). Accompanying the tendency of political journalism, it is the game and not the politics in negotiations that is highlighted by the press whose dominant discourse hit the formation of a Left Government for economic and symbolic reasons.

Keywords: Political journalism; Agenda-Setting; Framing; Left Government; Media and Democracy. 


\section{Introdução}

Das eleições legislativas de 4 de Outubro de 2015 resultou uma situação inédita em Portugal: o Partido Socialista (PS) derrotado nas urnas conseguiu formar Governo ao garantir o apoio de uma maioria de esquerda com partidos desde sempre arredados do poder - Partido Comunista Português (PCP), Bloco de Esquerda (BE) e Partido Ecologista Os Verdes (PEV). A coligação que venceu as eleições composta pelo Partido Social-Democrata (PSD) e pelo Centro Democrático Social (CDS) viu-se fora do executivo, depois de chumbado o seu programa no Parlamento. Nunca tal tinha acontecido. O partido vencedor constituíra sempre Governo. E uma solução de esquerda nunca tinha sido ensaiada no país. Revolta, surpresa e ceticismo acompanharam esses dias agitados na esfera política e mediática de um país que tinha acabado de sair de uma grave crise financeira que obrigara a um pedido de ajuda externa. Em 2011, a Troika (constituída pelo Fundo Monetário Internacional, Banco Central Europeu e Comissão Europeia) chegou a Portugal com um Programa de Assistência Económica e Financeira (PAEF) marcado por fortes medidas de austeridade. A intervenção terminou em Junho de 2015. Nas eleições que se seguiram em Outubro, o PS ficou em segundo lugar com 32,32 \% dos votos e a coligação "Portugal à Frente", constituída pelos partidos que aplicaram as impopulares medidas (PSD-CDS) venceu com 36,86\%. Sem maioria absoluta, PSD e CDS formaram Governo mas o chumbo do seu programa no Parlamento obrigou à sua resignação, conforme dita a Constituição ${ }^{1}$. Consequentemente, o Presidente da Republica, apesar de contrariado, viu-se obrigado a procurar outra solução que começava a ser desenhada pelos partidos da esquerda parlamentar (Fernandes e Jalali, 2017: 129). Com efeito, o PS reuniu o apoio do PCP, BE e PEV e apresentou-se em Belém pronto para governar com uma fórmula que, até esse momento, nunca tinha sido testada no país - um governo minoritário do PS apoiado na Assembleia da Republica pelas forças partidárias da esquerda, tradicionalmente forças de oposição.

Ao analisar a realidade portuguesa, Carlos Jalali aponta precisamente a exclusão do PCP como "uma das características fundamentais do sistema de partidos e dos alinhamentos eleitorais", (Jalali, 2007:75) num sistema partidário em que uma "cumplicidade entre PS e PSD viria a permanecer uma dinâmica central" (Jalali, 2007:77). Como também constata Marco Lisi, "os dois partidos moderados e do centro (PS e PSD) dominaram sempre a composição do governo em Portugal, sozinhos ou em coligação com o pequeno partido da direita CDS-PP"2 (Lisi, 2016:4). Foi essa lógica que se viu quebrada nesta altura com a constituição de uma solução mais tarde popularizada de "Geringonça"3. Ao mesmo tempo que os críticos deste entendimento insistiam em dar-Ihe uma conotação negativa, os próprios foram apropriando o nome para Ihe dar sentido inverso, apostados em contrariar o ceticismo com que foram recebidos dentro e fora do país, tentando mostrar a sua eficácia na produção de resultados ${ }^{4}$. Esse ceticismo foi evidente nos media que,

\footnotetext{
${ }^{1}$ De acordo com a alínea d) do no 1 do artigo 195 da Constituição da Republica Portuguesa, a rejeição do programa do Governo implica a sua demissão.

${ }^{2}$ Todas as citações originalmente publicadas em língua estrangeira foram traduzidas pela autora.

${ }^{3}$ Vasco Pulido Valente assinou a crónica "A Geringonça" no jornal Público de 31 de Agosto de 2014. 0 autor descrevia assim o Partido Socialista, como "um partido desorganizado e dividido" em período de campanha para as suas eleições primárias que opunham António Costa a António José Seguro. Foi a primeira vez que surgiu tal referência. O termo foi posteriormente utilizado pelo presidente do CDS Paulo Portas, num debate parlamentar, para descrever o Governo PS com o apoio das esquerdas.

4 "É geringonça mas funciona (...) Até posso acrescentar mais: a nós não nos incomoda nada ser geringonça, mas a vocês incomoda-vos muito que funcione", respondeu o Primeiro-Ministro António Costa aos deputados no debate quinzenal na Assembleia da Republica de 28 de Abril de 2016 (https://www.publico.pt/2016/04/28/politica/noticia/sim-sim-egeringonca-mas-funciona-atira-costa-a-direita-1730432 consultado em 31.10.2017).
} 
segundo Helena Sousa e Luis António Santos (2014) adotaram um papel legitimador do programa de austeridade, entendendo-o como necessário para melhorar a situação do país. Estes autores consideram que "ao contrário dos movimentos nas redes sociais e das manifestações nas ruas, os media generalistas e económicos contribuíram para a «fabricação do consentimento» sobre o programa da troika." (Sousa e Santos, 2014:59) Um jornalismo pouco crítico, fruto das condições de trabalho e da insegurança profissional, conduziram, na sua opinião, a uma reprodução do discurso do poder. Partilhando deste entendimento, João Castro Caldas e João Ramos de Almeida, analisando as crónicas e os editoriais de seis jornalistas económicos publicados entre 2010 e 2014, concluíram que estes se focavam na culpa, na inevitabilidade e no sacrifício. De acordo com estes investigadores, o discurso jornalístico contribuiu para a fabricação do consentimento "a partir da mistura de medo com persuasão" (apud Matos, 2017:39). A legitimação da austeridade foi, de resto, uma tendência não só portuguesa como europeia (Basu, Schifferes and Knowles, 2018). Em todos os países que se viram confrontados com a crise das dívidas soberanas, os media enquadraram uma resposta única centrada na austeridade, sem espaço para uma política alternativa. Foi assim na Grécia (Doudaki, 2015) e na Irlanda (Paschal and Silke, 2014).

Será esta visão determinante para a forma como os media portugueses contaram os dias agitados que se seguiram às eleições de 4 de Outubro de 2015? Que enquadramento escolheram? Que narrativa jornalística foi construída pelos media a partir das negociações políticas que ameaçavam romper a tradição? Que "geringonça" foi montada mediaticamente? É a partir destas questões que olhamos para as capas dos jornais e seus editoriais procurando caracterizar a resposta mediática a um dos períodos mais turbulentos da democracia portuguesa, como refere Jorge M. Fernandes (2016:8):"um sismo político que abalou algumas certezas da política portuguesa estabelecidas desde a democratização." Antes disso, procuramos identificar as principais tendências do jornalismo político enquanto ator do próprio processo político.

\section{O jornalismo como ator político}

Os acontecimentos chegam aos cidadãos através das notícias. É a partir delas que estes constroem a sua visão do mundo. Enquanto produtores de sentido (Schudson, 2011), os jornalistas desempenham deste modo um papel decisivo na configuração da realidade por parte do público. Pela seleção noticiosa que fazem e pela forma como contam as estórias. O papel de definidor da agenda pública - "agenda-setting" desempenhado pelos media através da relevância/saliência dada a determinados temas é revelador da sua importância no desenho do consenso social (McCombs, 1997). Os media gizam a ordem do dia da comunidade e através do enquadramento dado às notícias - "framing " - contribuem para a definição do ângulo da sua compreensão. Joseph N. Cappella e Kathleen Hall Jamieson (1996), entendem-no como um processo subtil que acaba por determinar a forma como os cidadãos apreendem o mundo. Estes autores defendem que o tipo de cobertura das notícias políticas, privilegiando a estratégia em detrimento da substância, cria um olhar cínico sobre a política. O destaque dado a um ângulo em detrimento de outro favorece uma certa leitura do fenómeno social manifestando um exercício de autoridade desenvolvido pelo jornalista. Robert M. Entman (2007) encara-o como uma manifestação de poder que ativa quadros de configuração mental, um processo omnipresente que "envolve a seleção de alguns aspetos de uma realidade entendida e a sua ligação numa narrativa que promove uma interpretação particular" (Entman, 2010:391). Neste processo joga-se o poder de delinear formas de entendimento do mundo, "tornando salientes alguns 
aspetos, obscurecendo outros, sugerindo juízos morais e modos de ação" (Gradim, 2016:90). Esta perspetiva acaba por questionar a objetividade sagrada da profissão jornalística enquanto bandeira e selo de credibilidade. Gaye Tuchman entende-a antes como "um ritual estratégico, protegendo os jornalistas dos riscos da sua profissão" (apud Traquina, 1993:74). Um traço distintivo de uma atividade que não atua numa esfera isolada. O trabalho jornalístico interfere (Negrine, 1996) e funciona como intermediário (Davis, 2009) no processo político. Neste cenário, os atores do jogo político ativam mecanismos de competição na sua relação de interdependência em busca de protagonismo e domínio mediáticos. Os políticos necessitam dos media para terem visibilidade junto dos cidadãos. Os media precisam dos políticos para terem notícias desenvolvendo deste modo uma relação simbiótica de mútua dependência (Gans, 1980). Apesar da tensão existente entre as duas esferas, política e media alimentam uma relação simbiótica de interdependência fundamental para a sobrevivência de ambas. Para José Manuel Paquete de Oliveira "sistema político e sistema mediático estão de tal maneira entrelaçados, interligados, que sofrem de uma crónica dimensão siamesa" (Oliveira, 2017:463). Nelson Traquina defende que "enquanto o acontecimento cria a notícia, a notícia também cria o acontecimento." (Traquina, 1993:168). Os jornalistas acabam por ser participantes ativos na realidade que transmitem, atores políticos (Cook, 2011; Serrano, 2006) e participantes diretos nas estórias que contam (Patterson, 2003), privilegiando o estilo interpretativo dos acontecimentos em detrimento do simples relato, reforçando desse modo o seu poder sobre a notícia. Com efeito, os media não se limitam ao papel de observador e a fazer a mediação entre os vários atores sociais. Participam na construção dessa relação disseminando os seus mecanismos para as restantes esferas sociais. O conceito de mediatização descreve o processo através do qual o sistema político incorporou as regras e os mecanismos dos media, que se transformou em "campo de batalha pelo poder" (Castells, 2003:414).

Stig Hjarvard explica que a mediatização da sociedade incorpora um processo em que esta "submete-se ou torna-se dependente dos media e da sua lógica" (Hjarvard, 2008:113). Cenário, horário, protagonistas, discurso, tudo é planeado em função do meio de transmissão televisiva e dos seus códigos. A simplificação, a personalização, o jogo político, o conflito são eixos da lógica mediática apreendidos por quem quer aparecer. Apesar de tudo, este autor considera que embora manifestem uma dependência crescente à lógica mediática à qual têm tido de se adaptar, "as instituições políticas como parlamentos, partidos, etc., continuam em grande medida a controlar a política" (Hjarvard, 2008:107). Também Gianpietro Mazzoleni e Winfried Schulz encontram na Europa padrões de defesa nos sistemas político e mediático que travam uma influência mútua excessiva:" 'media politics' não significa 'politics by the media'" (Mazzoleni e Schulz, 1999:260). Thomas Meyer e Lew Hinchman entendem pelo contrário que os media colonizaram a política na medida em que as regras do sistema mediático dominam a esfera política. Estes autores falam em democracia mediatizada enquanto "novo regime político ou constituição com as suas próprias regras, constrangimentos, opções, recursos, canais de influência e limitações" (Meyer e Hinchman, 2002:viii). Esta realidade é evidente no dia-a-dia político. Os próprios processos de negociação, que se por natureza implicam segredo e discrição, acabam por ser "invadidos" pela lógica mediática podendo dificultar o próprio desfecho. Doreen Spörer-Wagner e Frank Marcinkowski falam em "negociação mediatizada" em que "os negociadores consideram e empregam estratégicas mediáticas que complementam ou substituem as rotinas negociais típicas" (Spörer-Wagner e Marcinkowski, 2010:20). Estas incluem fugas para os media para causarem impacto nas negociações e reforçarem o poder negocial de uma das partes. Partindo da incompatibilidade entre publicidade mediática e privacidade negocial, estes autores estudam a negociação política na Alemanha a partir da adaptação à nova lógica mediática das rotinas políticas negociais, que 
pressupõem um elevado nível de confiança entre os negociadores com vista a alcançarem um compromisso. David Stasavage entende por seu lado que discussões à porta aberta encorajam os participantes e adotarem "posições negociais agressivas que aumentam o risco de falhanço nas negociações" (Stasavage, 2004:695). Investigadores como Cappella e Jamieson (1997) e Blumler (1997) entendem que a forma como os media apresentam a política cria desconfiança e cinismo junto dos eleitores sendo responsável pela sua apatia cívica. Patterson (1994) considera que a valorização da estratégia do jogo político em detrimento da substância das políticas, por aquela encaixar melhor na lógica do processo noticioso, contribui para este alheamento social. Menos apocalítica, Pippa Norris (2000) recusa atribuir ao jornalismo a civic malaise descrevendo até um 'círculo virtuoso' sobre a atenção dada às notícias políticas.

A teoria crítica tem demonstrado, por seu lado, que o padrão de cobertura noticiosa favorece a estrutura de poder dominante dificultando a mudança social (Lichter, 2017). Com o seu modelo de propaganda, Herman e Chomsky mostram como a atuação dos media contribui para manter a agenda dominante: "através da seleção dos tópicos, distribuição de preocupações, enquadramento das matérias, filtros informativos, destaque e tom, e mantendo o debate dentro das premissas aceitáveis" (1994: 298). A partir da análise da abordagem jornalística britânica sobre o líder do Partido Trabalhista Jeremy Corbyn, Cammaerts et.al demonstram como o alinhamento dos media com o status quo determina a forma como são tratados os atores que desafiam essa ordem. Os autores defendem que os papeis tradicionais do jornalista enquanto watchdog, de vigilante, e colaborativo com a estrutura empresarial são transformados em attackdog (cães de ataque) "deslegitimando os atores políticos que ousam desafiar o status quo" (Cammaerts et.al, s.a.:3)

\section{Metodologia}

Este artigo, que se insere numa investigação mais ampla sobre o jornalismo político e o relacionamento entre jornalistas e fontes na construção noticiosa da "geringonça", centra-se nos títulos das capas dos jornais e nos editoriais. O objetivo é captar a importância e o enquadramento jornalístico dado à formação do Governo do PS com o apoio parlamentar dos partidos de esquerda. Olhamos para as primeiras páginas enquanto montra onde os jornais "vendem" o seu produto razão pela qual a seleção dos títulos não é indiferente. Curtos, compreensíveis e sumários da notícia a que estão associados, estes devem ser apelativos de modo a atrair a atenção do leitor e cativá-lo a ler o texto, o que nem sempre acontece. Daniel Dor afirma que "a maioria dos leitores dedica mais tempo a espreitar as manchetes do que a ler as notícias" (Dor, 2003:718). Esta perceção justifica ainda mais a atenção que o discurso presente nas capas dos jornais deve suscitar dada a sua influência no debate social com os enquadramentos dados à informação. Dor entende os títulos como relevance optimizers, "eles servem para otimizar a relevância das estórias aos seus leitores." (Dor, 2003:696) E apesar de por vezes existir dissonância entre os títulos e os textos jornalísticos a que correspondem, ambos condicionam fortemente as atitudes dos leitores (Andrew, 2007).

Além da informação presente nas capas dos jornais, analisamos os seus editoriais, entendidos por Fernando António de Azevedo como a "alma dos veículos" (apud Oliveira, 2018:6). Christiane Eilders entende que a intenção dos editoriais é influenciar o processo político. Com a escolha do tema, o ângulo de análise, enquadrando a matéria e analisando protagonistas, o autor do editorial, membro do pequeno grupo que dirige a publicação e que por ela assina, manifesta em poucas linhas o seu domínio. Como nota Eilders "através dos editoriais os media estão autorizados claramente a expressar as suas opiniões e ao comentar 
os acontecimentos fazem uso do seu direito a apresentarem-se como atores autónomos"' (Eilders, 1997:7). Sem preocupações de distanciamento como acontece nas notícias, os responsáveis da publicação manifestam no editorial a sua perspetiva sobre determinado acontecimento e a sua estratégia face ao mesmo posicionando-se no campo político (Marques, Mont'Alverne e Mitozo, 2018). Trata-se de um espaço de liberdade no qual confluem olhares e posicionamentos da direção do jornal, que reflete a posição dominante das publicações. Expressão da linha de pensamento do jornal, os editoriais permitem-nos entender a sua tendência central. Aqui, quem escreve assume claramente uma posição sobre determinado tema afastando-se da objetividade defendida nos manuais de produção jornalística.

Da imprensa tradicional escolhemos para a nossa pesquisa quatro diários de características diferentes - dois jornais considerados de "referência" (Diário de Notícias e Publico) e outro de cariz popular (Correio da Manhã). A escolha do Diário de Notícias e do Publico prende-se com a importância que ambos dão à atualidade política, tendo equipas especializadas nesta área que produzem informação que, muitas vezes, é desenvolvida por outros media. O Correio da Manhã é, por seu lado, pertinente na medida da sua popularidade - é o jornal com maior tiragem do país 5 - o que o torna apetecível para as fontes interessadas em disseminar a sua mensagem pelo maior numero de leitores/cidadãos. Julgámos também imprescindível incluir um novo meio digital - o jornal online Observador - um projeto que, assente em grande medida na atualidade política, introduziu novas formas de fazer com a sua estratégia de publicação imediata das notícias.

Com o objetivo de focarmos a nossa análise no produto jornalístico assinado por jornalistas, excluímos textos de análise e opiniões de autores que não pertencem a este campo (comentadores, políticos, etc). Assim, para entendermos como a informação contribui para a construção da perceção do fenómeno político, centramo-nos nos editoriais e nos títulos das notícias "puras e duras" de capa, estas enquanto produto principal da atividade dos media, em que a objetividade surge normalmente associada aos padrões evocados pelos seus profissionais, em contraste com a subjetividade marcada nos primeiros. Ambos - editoriais e títulos de capa - são redigidos por membros da Direção dos jornais (exceto no caso do Observador).

Para o estudo dos títulos de capa, o nosso corpus é composto por 639 títulos que figuram nas primeiras páginas de todos os jornais Público $(n=127)$, Diário de Notícias $(n=226)$, Correio da Manhã $(n=124)$ e Observador $(n=162)$ publicados entre 5 de Outubro de 2015 - o dia seguinte às eleições legislativas - e 4 de Dezembro de 2015 - o dia seguinte à aprovação do programa do Governo do PS na Assembleia da Republica. Recolhidas as 61 capas de cada publicação $(n=244)$, procedemos ao registo das primeiras páginas que fazem referência à formação do Governo e respetivas movimentações políticas - Diário de Notícias $n=61$, Público $n=57$, Correio da Manhã $n=57$, Observador $n=58$. A recolha dos jornais impressos foi realizada na Hemeroteca Municipal de Lisboa onde fotografámos as primeiras páginas das edições correspondentes ao período em análise. A recolha das notícias do Observador foi feita no dia 06/04/2018 no site Arquivo.pt, uma ferramenta de investigação disponibilizada pela Fundação para a Ciência e Tecnologia, que guarda páginas da web. Como por vezes havia duas edições, recolhemos sempre a edição das 18:02. Se a manchete não oferece dúvidas em qualquer dos jornais, note-se que no caso do Observador considerámos como chamadas à primeira página os títulos que surgiam até duas linhas abaixo da manchete.

\footnotetext{
${ }^{5}$ De acordo com a APCT - Associação Portuguesa para o Controlo da Tiragem e Circulação, o Correio da Manhã, mantendo uma tendência que se prolonga até hoje, liderava a tabela de tiragens, no período em análise, com 147.150 exemplares no $5^{\circ}$ bimestre de 2015 e 141.546 no $2^{\circ}$ bimestre de 2015. O Publico apresentava 33.739 exemplares ( $5^{\circ}$ bimestre de 2015) e 32.753 exemplares ( $6^{\circ}$ bimestre de 2015) O Diário de Notícias registava 27.804 ( $5^{\circ}$ bimestre de 2015) e 26.819 (60 bimestre de 2015).
} 
A análise dos editoriais obedeceu à mesma regra. A partir da consulta dos editoriais da totalidade dos jornais da nossa amostra $(n=244)$, retivemos aqueles que incidiam sobre a formação do Governo resultante das eleições legislativas ( $n=123$ ): Publico $n=43$, Diário de Notícias $n=34$, Correio da Manhã $n=34$, Observador $\mathrm{n}=12$

Pretendíamos ter resposta às seguintes questões: Que destaque deram os jornais à formação do Governo? Qual o enquadramento(s) jornalístico(s) mais apelativo(s) ? De que forma foi noticiado um processo que abalava o status quo da política nacional? Recorremos a uma metodologia mista para procurar responder à nossa pergunta de partida: De que modo os media noticiaram a formação do Governo resultante das eleições legislativas de 2015? Partimos das seguintes hipóteses:

H1: Os jornais construíram uma narrativa crítica sobre a formação de um Governo de esquerda.

H2: Os jornais demonstraram o seu alinhamento com a tradição política resistindo à mudança.

H3: Os jornais privilegiaram o Jogo em detrimento das Políticas no enquadramento noticioso da formação do Governo.

Começámos por utilizar uma metodologia quantitativa para registar a frequência do tema nas capas dos jornais (manchete/chamada à primeira página/sem referência) e nos editoriais. Procurámos também verificar quais os protagonistas mais em foco (personalidade política/partido). Depois do registo das incidências recorremos a uma metodologia qualitativa manual para, através de uma análise de conteúdo (Bardin, 2014) dos títulos e dos editoriais, detetar o tipo de enquadramento privilegiado.

No estudo dos títulos, procedemos a uma análise de conteúdo sobre o material recolhido com base na tipologia construída por Thomas E. Patterson na pesquisa sobre as estórias eleitorais das capas do New York Times entre 1960-1992 para captar o tipo de enfoque escolhido: Jogo/Políticas (Game Schema/ Policy Schema) ${ }^{6}$. Enquanto o primeiro eixo abarca as movimentações e as estratégias desenvolvidas pelos atores sociais na arena política, o segundo incide sobre o conteúdo de políticas concretas. Apesar de outros autores (Aaalberg, Strömbäck and de Vreese, 2011) fazerem uma distinção entre Jogo e Estratégia (Game Frame/Strategy Frame), julgamos que a conceptualização de Patterson é positivamente abrangente para centrar a nossa análise uma vez que abarca elementos que se dicotomizam naquela nova abordagem (estratégias e táticas, linguagem de guerra, motivações dos atores, vencedores e derrotados). Robert M. Entman também procede a uma distinção entre enquadramento substantivo e processual "com o ultimo focado na avaliação da estratégia política, na "corrida de cavalos" e na luta de poder entre as elites, em lugar da natureza substantiva e no significado das questões, eventos e atores" (Entman, Matthes and Pellicano, 2009:176)

Para uma análise dos editoriais seguimos também o conceito de enquadramento de Entman (2007) segundo o qual os frames podem englobar quatro funções: a definição do problema, uma análise das causas, um julgamento moral e a recomendação de uma solução. Procedemos neste caso a uma análise temática dos textos identificando a problemática, as suas causas, argumentos e soluções. Depois de uma leitura inicial, procedemos a uma categorização da narrativa sobre a discussão da solução política a partir destas quatro variáveis.

\footnotetext{
6 "As notícias eram colocadas na categoria de jogo se fossem enquadradas no contexto de estratégia e sucesso eleitoral. Estórias eram colocadas na categoria de substância se enquadradas no contexto de políticas e problemas de liderança." (Patterson, T.E., 1994:74)
} 


\section{Resultados}

Nas 61 edições de cada jornal que saíram durante os dois meses a que se refere a nossa pesquisa, a formação do Governo cobriu diariamente as suas páginas tendo, na sua larga maioria, honras de capa. Esta escolha revela a importância deste acontecimento quase sempre presente na agenda mediática. Como mostra a tabela 1, o Diário de Notícias chamou o tema todos os dias à primeira página. O Publico só não o fez em 4 edições, o Correio da Manhã em 5 e o Observador em 10.

Tabela 1: A formação do Governo nas capas dos jornais e seus editoriais

\begin{tabular}{|c|c|c|c|c|c|}
\hline & \multicolumn{2}{|c|}{ CAPAS } & & EDITORIAIS & TOTAL \\
\hline & MANCHETES & $\begin{array}{l}\text { CHAMADAS A } \\
\text { PRIMEIRA } \\
\text { PÁGINA }\end{array}$ & $\begin{array}{c}\text { SEM } \\
\text { REFERÊNCIA }\end{array}$ & & \\
\hline PÚBLICO & $34(56 \%)$ & $23(38 \%)$ & $4(6 \%)$ & $43(70 \%)$ & $61(100 \%)$ \\
\hline DIÁRIO DE NOTÍCIAS & $30(49 \%)$ & $31(51 \%)$ & 0 & $34(56 \%)$ & $61(100 \%)$ \\
\hline CORREIO DA MANHÃ & $13(21 \%)$ & $43(70 \%)$ & $5(9 \%)$ & $34(56 \%)$ & $61(100 \%)$ \\
\hline OBSERVADOR & $31(51 \%)$ & $20(33 \%)$ & $10(16 \%)$ & $12(20 \%)$ & $61(100 \%)$ \\
\hline
\end{tabular}

Fonte: elaboração própria

Os jornais contribuíram para a fixação do debate político na agenda mediática. Nunca largando o tema da sua página nobre, a imprensa refletiu o intenso período político negocial a que se assistiu. Com o SecretárioGeral do PS como protagonista-chave. Apesar de não ter ganho as Legislativas, António Costa revelou-se a figura principal do cenário pós eleitoral. Como mostra a tabela seguinte, o líder socialista tem 171 referências nos títulos (41 das quais nas manchetes), o presidente do PSD Pedro Passos Coelho, 100 (22 manchetes) e o Presidente da Republica Cavaco Silva, 97 (19 manchetes). 20 títulos fazem referência aos restantes atores político: o líder do CDS Paulo Portas (3 manchetes), 9 à coordenadora do BE Catarina Martins (2 manchetes) e 6 ao Secretário-Geral do PCP Jerónimo de Sousa (1 manchete). 
Tabela 2: Os líderes políticos nas primeiras páginas

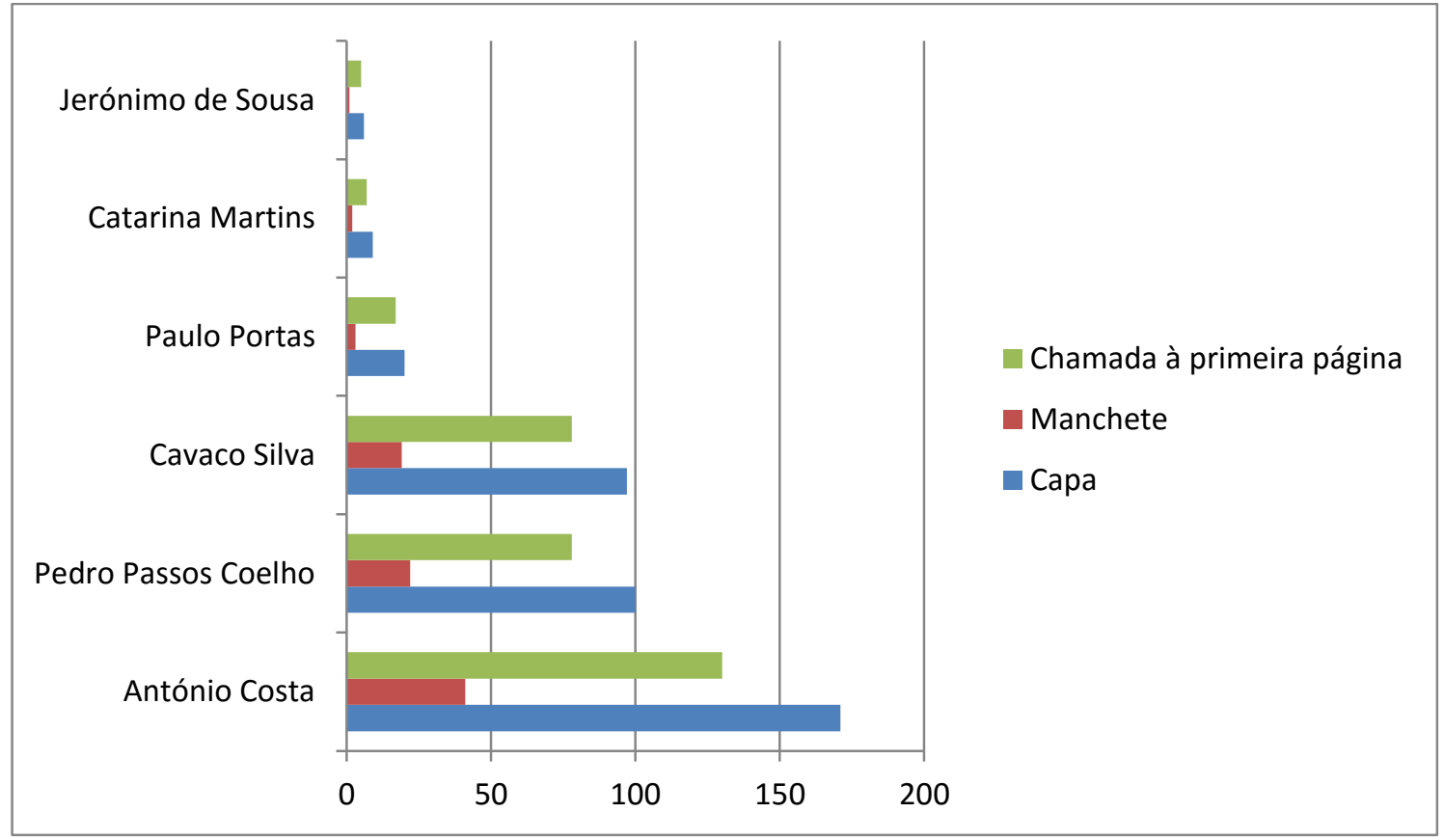

Fonte: Elaboração própria

Na referência partidária, o destaque é ainda mais evidente. Apesar de terem vencido as eleições, PSD e CDS "cedem" o protagonismo mediático aos partidos de esquerda nas primeiras páginas dos jornais. Como mostra a tabela seguinte, o PS tem 119 referências (18 em manchete), o PCP 63 (11 manchetes), o BE 51 (7 manchetes), o PSD 23 (1 manchete), o CDS 16 (1 manchete), o PEV 4 (1 manchete). No binómio político Esquerda-Direita, a referência à Esquerda é maioritária com 86 registos (23 manchetes). A Direita surge 15 vezes (4 manchetes).

Tabela 3: Os partidos políticos nas primeiras páginas

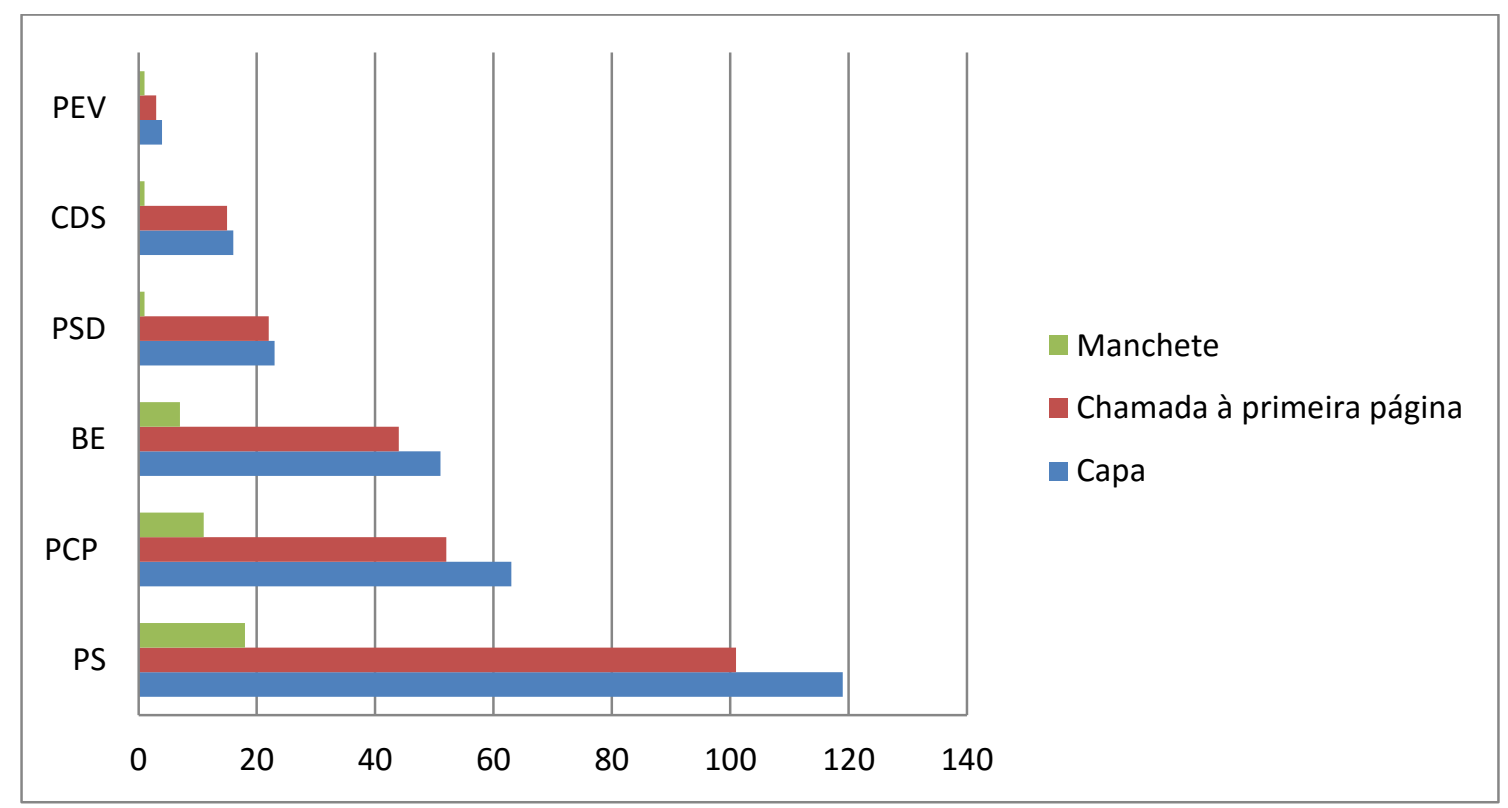

Fonte: Elaboração própria 
Acompanhando a tendência do jornalismo político que apresentámos atrás, as primeiras páginas dos jornais incidiram durante estes 61 dias sobre o Jogo da negociação em detrimento das Políticas que a materializavam. Tendo em conta o contexto negocial, esta realidade torna-se mais evidente e pouco surpreendente mas confirma a valorização deste enquadramento na saliência jornalística. Dos 639 títulos que compõem o nosso corpus, $76 \%(n=487)$ incidem sobre a temática do Jogo (82 manchetes +405 chamadas à primeira página) e $22 \%(n=142)$ sobre Políticas ( 26 manchetes +116 chamadas à primeira página) ${ }^{7}$. A tabela 4 apresenta essa distribuição por jornal.

Tabela 4: Enquadramento dos títulos das capas dos jornais

\begin{tabular}{|c|c|c|c|c|c|}
\hline & \multicolumn{2}{|c|}{ JOGO } & \multicolumn{2}{|c|}{ POLITICAS } & TOTAL \\
\hline & MANCHETE & $\begin{array}{l}\text { CHAMADA A } \\
\text { PRIMEIRA } \\
\text { PÁGINA }\end{array}$ & MANCHEIE & $\begin{array}{l}\text { CHAMADA } \\
\text { A } \\
\text { PRIMEIRA } \\
\text { PÁGINA }\end{array}$ & \\
\hline PÚBLICO & $31(24,5 \%)$ & $73(57,5 \%)$ & $3(2 \%)$ & $19(15 \%)$ & $127(100 \%) *$ \\
\hline DIÁRIO DE NOTÍCIAS & $23(10 \%)$ & $153(68 \%)$ & $7(3 \%)$ & $37(16 \%)$ & $226(100 \%)^{* *}$ \\
\hline CORREIO DA MANHÃ & $6(5 \%)$ & $77(62 \%)$ & $7(6 \%)$ & $32(26 \%)$ & $124(100 \%)^{* * *}$ \\
\hline OBSERVADOR & $22(13 \%)$ & $102(63 \%)$ & $9(6 \%)$ & $28(17 \%)$ & $162(100 \%)^{* * * *}$ \\
\hline
\end{tabular}

Fonte: elaboração própria

*um título (1\%) não se enquadra em qualquer das categorias; **seis títulos (3\%) não se enquadram em qualquer das categorias; $* * *$ dois títulos (1\%) não se enquadram em qualquer das categorias; $* * * *$ um título (1\%) não se enquadra em qualquer das categorias

Os títulos são dominados pelos códigos de Jogo ("Costa - Xeque-mate ou "reflexo do náufrago?", Observador 10/10/2015; "Passos e Portas traçam linha vermelha ao PS", DN 05/11/2015; "Orçamento rápido é trunfo para Costa apresentar a Cavaco Silva", DN 23/11/2018) e pela linguagem bélica (" Esquerda ganha primeira batalha", CM 24/10/2018; "Francisco Assis vai correr o país em cruzada contra acordo à esquerda", DN 01/11/2018; "Acordos à esquerda blindam governo PS de moções de censura", Publico 9/11/2018; "Costa arma PS para combater Passos e Portas", DN 24/11/2015; "Combate de Costa começa agora", Publico 24/11/2018).

A estratégia e as táticas das movimentações negociais dominam as primeiras páginas que, para lá de relatarem o passado, tentam antecipar o futuro ("Cavaco tenciona insistir nas dificuldades do país ao dar posse a Costa", Publico 26/11/2015) e nos avisos aos interlocutores políticos na véspera das reuniões ("Passos rejeita medidas que ameacem metas orçamentais, DN 8/10/2015). Rompendo a tradição jornalística assente dos títulos declarativos, o Observador aposta nas manchetes interrogativas ("Até onde

\footnotetext{
${ }^{7}$ Dez títulos (2\%) não são enquadráveis nas categorias Jogo/Políticas.
} 
cedem PCP e BE? Como fica o programa de Centeno? Que hipóteses tem ainda Passos?", Observador 14/10/2015) mostrando não se importar em mostrar que o jornalista não tem resposta para tudo, evidenciando a incerteza do cenário político ("Duvida. Como votarão PCP e Bloco?", Observador 4/11/2015), e um gosto pouco habitual por números ("Esquerda unida? 9 sinais de fragilidade do acordo", Observador 23/11/2015; "Os 24 compromissos de António Costa", Observador 3/12/2015).

Da menor fatia que as capas dos jornais dedicam às Políticas sobressaem as medidas económicas. Pensões, Salários, Sobretaxa, IRS e Taxa Social Única dominam esta área que os jornais não observam da mesma maneira, como mostra a tabela 4. É o Correio da Manhã, jornal de característica popular, que mais escolhe as matérias de substância para manchete. Das treze vezes que dedicou o título garrafal da sua edição ao processo pós-eleitoral, sete foram para chamar a atenção sobre Políticas "Passos cede a Costa na carga do IRS-Sobretaxa devolvida em 3 anos", 10/10/2015; Acordo PS/CDU/BE prevê reposição de salários em 2016", 30/10/2015; "Salários e pensões sobem em 2016", 06/11/2015; "Telefones pagam taxa da RTP", 11/11/2015; "IRS - Classe média dá 350 milhões a pobres - Escalão negativo do imposto dá dinheiro a ordenados abaixo do salário mínimo", 14/11/2015; " Costa dá mais de mil milhões às famílias", 27/11/2015; "Esquerda acaba com exames do 40 ano", 28/11/2015).

O Observador também deu o maior relevo ao foco das Políticas mas numa análise mais apurada das manchetes registamos uma relação de menor dimensão comparativamente com o Correio da Manhã. Enquanto neste mais de metade das manchetes foi sobre esta temática, no Observador foram 9 em 31 ("Esquerda unida: 13 leis para cair.28 para impor. Alterar a lei das rendas, baixar o IVA da restauração, repor as 35 horas e dois feriados", 8/10/2015; "PS jura: 4 anos sem piorar salários nem impostos", 26/10/2015; "Medidas extra a votos no Parlamento", 4/11/2015; "Eis as medidas de Costa", 7/11/2015; "BE e PCP aceitam repor (parte dos) cortes este ano. Os deputados vão discutir no dia 26 o corte nos salários dos funcionários públicos e redução da sobretaxa, para que entrem em vigor a 1 de Janeiro", 11/11/2015; "Todos os nomes do novo Governo de Costa", 24/11/2015; "Os 41 novos secretários de estado", 25/11/2015; "Costa reintegra funcionários na requalificação. Costa reúne-se com patrões e sindicatos para a semana, propondo salario mínimo de 530 euros em 2016. Quer reverter concessões e promete 100 milhões para empresas nos primeiros 100 dias" 2/12/2015; "Que herança recebe o Governo PS", 4/11/2015).

No Diário de Notícias, sete das 30 manchetes foram sobre Políticas ("Passos rejeita medidas que ameacem metas orçamentais", 8/10/2015; "Costa dá prioridade a famílias mais pobres", 13/10/2015; "PS ainda faz contas a sobretaxa e salário mínimo", 26/10/2015; "Sobretaxa só cai um terço", 5/11/2015; "TransportesIdeias do PS têm riscos financeiros elevados", 10/11/2015; "Costa já decidiu-Escalões do IRS só mudam em 2017", 26/11/2015; "Governo vai dar bónus a quem desconte mais de 40 anos", 2/12/2015; ". No Público, apenas 3 em 34 ("Costa acena com acordo à esquerda assente nas pensões e nos salários", 21/10/2015; "Governo aprova hoje medidas para manter austeridade em 2016", 5/11/2015; "Alívio da sobretaxa de IRS e cortes salariais nas mãos do Parlamento", 6/11/2015).

Nestes três jornais é significativa a escolha por títulos sobre o jogo negocial em curso, numa lógica discursiva horizontal entre jornalistas e fontes que alimenta uma bolha informativa em detrimento de uma cobertura vertical dirigida aos cidadãos que o foco sobre as políticas representa. Este enquadramento vai ao encontro da lógica mediática (Strömbäck, 2008) que envolve a lógica política. A escolha dos temas económicos é igualmente de sublinhar uma vez que demonstra a relevância noticiosa deste frame, compreensível no contexto de um país acabado de sair de uma grave crise financeira. 
A análise dos títulos das capas dos jornais mostra que a incerteza política resultante das eleições legislativas e consequentes movimentações produziu um caldo informativo à medida da lógica dos media. Para aprofundarmos o sentido presente nas primeiras páginas, definimos duas categorias de análise com base na leitura dos títulos: Estabilidade/Instabilidade. Com efeito, é em torno destes dois eixos centrais que o processo político que culminaria na formação da "geringonça" é apresentado aos leitores. Enquanto o primeiro cenário é associado à coligação PSD/CDS, o segundo acompanha as movimentações do PS e da esquerda. A divisão entre os socialistas ("Cavaco pede Governo estável a Passos. PS continua dividido", DN 07/10/2015), a desconfiança interna ("Demissão de Sousa Pinto revela cepticismo no PS com diálogo à esquerda", Publico 11/10/2015), os efeitos negativos de uma solução à esquerda ("Medo de Catarina assusta Bolsa", CM 13/10/2015) e o seu carácter opaco ("PS esconde acordo com PCP e Bloco", DN 22/10/2015), o afastamento eleitoral recente ("Esquerdas na campanha: tão amigos que (não) eram", Observador 16/10/2015) contrastam com o cenário sereno e otimista preconizado pela direita ("Cavaco e Coligação acreditam em acordo com PS para Orçamento", DN 06/10/2015).

A generosidade do líder do PSD ("Passos cede a Costa na carga do IRS", CM 10/10/2015) e a tentativa séria de alcançar um entendimento ("Coligação envia mais de 20 propostas ao PS e ainda confia num acordo" Publico 13/10/2015) esbarra num opositor calculista ("Costa. Xeque-mate ou "reflexo do náufrago"?, Observador 10/10/2015), mais centrado na tática política ("Costa testa acordos à esquerda", DN 08/10/2015) que não consegue pôr a casa em ordem ("Francisco Assis convoca opositores de Costa para encontro no sábado", Publico 03/11/2015) nem garantir uma alternativa segura ("Bloco e PCP mantêm em aberto possibilidade de deixar cair Costa", DN 11/11/2015). Um governo de esquerda causa preocupação financeira ("2 mil milhões fogem da Bolsa", CM 10/11/2015) num país a tentar levantar-se de um resgate após uma grave crise que obrigou à intervenção da Troika ("Bolsa tem a pior sessão desde o crash da China", Observador 09/11/2015) num período de boa governação ("Cavaco desdramatiza crise politica evocando tese dos cofres cheios", Publico 17/11/2015) ameaçada por um futuro socialista ("Transportes Ideias do PS têm riscos financeiros elevados", DN 10/11/2015).

\section{O papel do Presidente da Republica}

A análise das primeiras páginas dos jornais mostra também o relevo dado ao Presidente da Republica em todo este processo. Quer como protagonista dos títulos, quer das imagens, Cavaco Silva concorre com os potenciais Primeiros-Ministros António Costa e Pedro Passos Coelho (ver tabela 2). Com efeito, no sistema semi-presidencialista português, o chefe de Estado atua como "informateur com a capacidade de nomear um formateur com base nos resultados eleitorais" (Lisi, 2015:307). Apesar de não integrar a corrida eleitoral, acaba por participar na definição do futuro político do país. Elisabetta de Giorgi e José Santana-Pereira (2016) destacam o papel crucial do Chefe de Estado neste período porque, não defendendo uma solução que passasse pelas esquerdas, estava condicionado pelo próprio calendário presidencial (com eleições previstas para daí a poucos meses) o que limitava a sua ação impedindo-o de optar pela chave drástica que seria convocar novo sufrágio para a Assembleia da Republica. O próprio Presidente acabou assim por ser uma peça de destaque no tabuleiro das negociações, protagonista por excelência das notícias sobre o período em análise. Determinando a sequência dos acontecimentos, o Cavaco Silva condicionou com as suas ações e as suas palavras o desenrolar dos mesmos, procurando não só participar na definição da solução 
política mas acima de tudo ser o seu "maestro" - "Cavaco indigita Passos e exclui PCP e BE do poder. Presidente coloca nos deputados, que hoje tomam posse no Parlamento, a decisão de garantir a estabilidade, sugerindo que chumbem a moção de rejeição prometida pela esquerda" Público, 23/10/2015; "Cavaco vai à Madeira sem pressa para decidir sobre governo", DN 16/11/2015; " Cavaco dá posse a Passos mas deixa recados a Costa, CM 31/10/2015; "Cavaco empata solução", CM 19/11/2015; "Cavaco avisa que pode demitir primeiro-ministro. Cavaco foi duro e fez um aviso sério a Costa dizendo que "só há um poder" que não tem, nestes seis meses, o de dissolução da Assembleia.", Observador 26/11/2015 - Este papel dáIhe relevo nas capas dos jornais e nos editoriais. Como veremos à frente, Cavaco Silva foi figura de destaque acentuadamente negativa nos editoriais.

\section{Editoriais - A elite jornalística preocupada com a "geringonça"}

Durante o período em análise - 61 dias -, a formação do Governo foi tema de 123 Editoriais - 43 do jornal Público, 34 do Diário de Notícias, 34 do Correio da Manhã e 12 do Observador (ver tabela 1). À exceção deste último, a relevância noticiosa captada nas primeiras páginas dos jornais, manifestou-se igualmente no espaço de opinião da Direção. Tirando o jornal Público, todos os restantes têm a assinatura do autor do texto. Ou seja, apesar de em todas as publicações o texto assumir uma posição que as vincula, no Diário de Notícias, Correio da Manhã e Observador, o leitor sabe quem escreve, o que the permite ir relacionando o pensamento expresso com o membro da Direção escolhido naquele dia para desempenhar tal papel. Os quatro jornais diferenciam-se pela seleção da página onde inserem o texto. O Publico e o Diário de Notícias registam-no habitualmente junto de outros textos de opinião mas distinguindo-o claramente. $O$ Correio da Manhã escolhe a última página para estampar o seu "Correio Direto", e várias vezes, no meio das notícias políticas surge uma coluna de opinião do Diretor do Jornal, que chega a não diferenciar-se das demais, e que também incluímos na nossa análise. No Observador, não Ihe chamam Editoriais mas as crónicas do Diretor e do Publisher (jornalistas), assumem esse carácter mostrando a linha editorial da publicação online.

Uma leitura inicial dos editoriais permitiu-nos definir um quadro de análise para os mesmos.

\begin{tabular}{|l|l|}
\hline & \\
\hline PROBLEMA & $\begin{array}{l}\text { - Desconfiança sobre Governo de esquerda } \\
\text { - Taticismo partidário } \\
\text { - Incerteza política/económica }\end{array}$ \\
\hline CAUSAS & $\begin{array}{l}\text { - Instabilidade política } \\
\text { - Instabilidade económica }\end{array}$ \\
\hline AVALIAÇÃo & - Tradição histórica \\
\hline & \\
\hline & - Apoio/Crítica a Passos Coelho \\
& - Apoio/Crítica a António Costa \\
& - Apoio/Crítica a Cavaco Silva \\
\hline
\end{tabular}




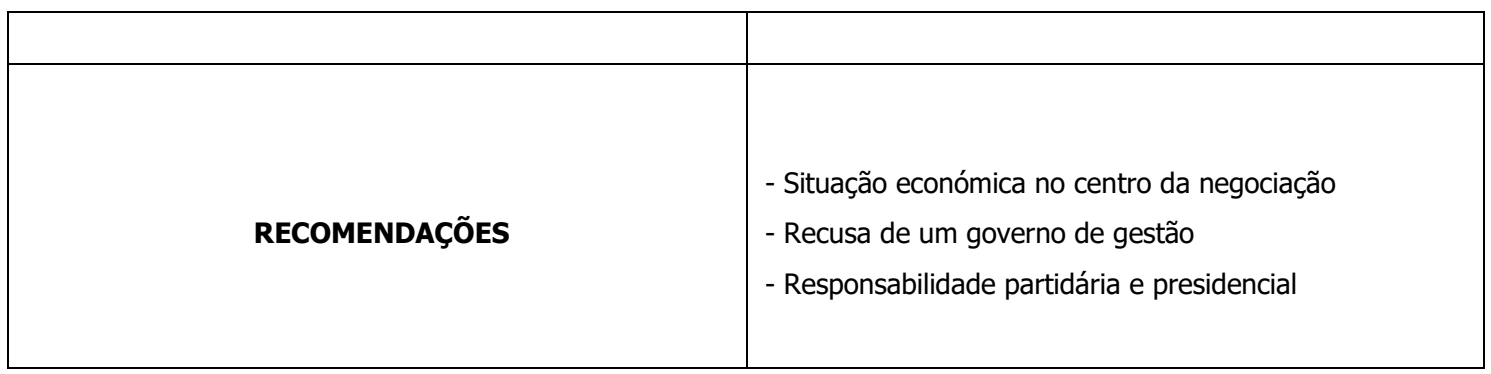

A análise dos 123 editoriais permite-nos captar o tom negativo sobre as negociações do PS com os partidos da esquerda parlamentar, as críticas à situação política e aos seus protagonistas (líderes partidários e Presidente da Republica) e a preocupação com uma realidade nunca testada em Portugal.

Tabela 5: Fatores de análise dominantes nos Editoriais

\begin{tabular}{|c|c|c|c|c|c|}
\hline & TOTAL & PUBLICO & DN & CM & OBSERVADOR \\
\hline $\begin{array}{l}\text { INSTABILIDADE } \\
\text { POLÍTICA }\end{array}$ & $\begin{array}{c}32 \\
(35 \%)\end{array}$ & $\begin{array}{c}4 \\
(17 \%)\end{array}$ & $\begin{array}{c}11 \\
(39 \%)\end{array}$ & $\begin{array}{c}11 \\
(44 \%)\end{array}$ & $\begin{array}{c}6 \\
(37 \%)\end{array}$ \\
\hline $\begin{array}{c}\text { INSTABILIDADE } \\
\text { ECONÓMICA }\end{array}$ & $\begin{array}{c}24 \\
26 \%)\end{array}$ & $\begin{array}{c}2 \\
(9 \%)\end{array}$ & $\begin{array}{c}8 \\
(29 \%)\end{array}$ & $\begin{array}{c}8 \\
(32 \%)\end{array}$ & $\begin{array}{c}6 \\
(37 \%)\end{array}$ \\
\hline TRADIÇÃO HISTÓRICA & $\begin{array}{c}12 \\
(13 \%)\end{array}$ & $\begin{array}{c}7 \\
(30 \%)\end{array}$ & $\begin{array}{c}1 \\
(3 \%)\end{array}$ & $\begin{array}{c}3 \\
(12 \%)\end{array}$ & $\begin{array}{c}1 \\
(7 \%)\end{array}$ \\
\hline $\begin{array}{c}\text { DESCONFIANÇA } \\
\text { SOBRE GOVERNO DE } \\
\text { ESQUERDA }\end{array}$ & $\begin{array}{c}10 \\
(11 \%)\end{array}$ & $\begin{array}{c}4 \\
(18 \%)\end{array}$ & $\begin{array}{c}3 \\
(11 \%)\end{array}$ & $\begin{array}{c}2 \\
(8 \%)\end{array}$ & $\begin{array}{c}1 \\
(7 \%)\end{array}$ \\
\hline TATICISMO POLÍTICO & $\begin{array}{c}8 \\
(9 \%)\end{array}$ & $\begin{array}{c}6 \\
(26 \%)\end{array}$ & $\begin{array}{c}2 \\
(7 \%)\end{array}$ & 0 & 0 \\
\hline OUTROS & $\begin{array}{c}5 \\
(6 \%)\end{array}$ & 0 & $\begin{array}{c}3 \\
(11 \%)\end{array}$ & $\begin{array}{c}1 \\
(4 \%)\end{array}$ & $\begin{array}{c}2 \\
(12 \%)\end{array}$ \\
\hline $\begin{array}{c}\text { TOTAL } \\
\text { DE FATORES }\end{array}$ & $\begin{array}{c}91 \\
(100 \%)\end{array}$ & $\begin{array}{c}23 \\
(100 \%)\end{array}$ & $\begin{array}{c}28 \\
(100 \%)\end{array}$ & $\begin{array}{c}25 \\
(100 \%)\end{array}$ & $\begin{array}{c}16 \\
(100 \%)\end{array}$ \\
\hline
\end{tabular}

Fonte: Elaboração própria

Adotando um posicionamento crítico e professoral, os autores dos editoriais desfazem cenários e aconselham os atores políticos. A instabilidade é a ideia central destes textos. Identificamos três eixos na recusa de um Governo do PS com o apoio dos partidos da esquerda parlamentar: Instabilidade, Economia, Tradição histórica. As críticas a um cenário inédito concentram-se nestes parâmetros. É por motivos económicos e simbólicos que o discurso jornalístico dominante chumba a "geringonça". A instabilidade política e económica de um eventual futuro Governo à esquerda é antecipada em todos os jornais. No Público prevê-se mais do que "uma incógnita. Se o PS seguir depois o seu natural caminho, mais convergente com o do actual Governo nas relações com a União Europeia e os credores, a «maioria de esquerda» ruirá e o PS terá na rua, contra si, os sindicatos e seus episódicos aliados. Se, pelo contrário, ceder a propostas mais à esquerda, terá de se haver com os mercados e os impiedosos credores." (12/10/2015) Dias antes no Diário de Notícias, André 
Macedo escreve que "um país governado também por comunistas e bloquistas é um mistério insondável, certamente um risco, provavelmente um animal de quatro patas traseiras." (9/10/2015) No Correio da Manhã, Armando Esteves Pereira vê custos na "manobra" de António Costa conseguir formar Governo: "pode haver eleições antecipadas e o PS do Governo à Syriza arrisca o mesmo futuro do Pasok: a irrelevância." (13/10/2015). David Dinis desabafa no Observador: " Não, não creio que tudo isto vá correr bem." (12/11/2015) No mesmo jornal online, num texto intitulado "Ai preocupem-se, preocupem-se...", José Manuel Fernandes escreve: "Sofreu-se muito para conter a subida da despesa pública, sofreu-se imenso para começar a adaptar a economia aos mercados abertos e competitivos destes tempo de globalização, penou-se sem fim para trazer os juros para os níveis a que estão, que permitem que Portugal se financie nos mercados, e tudo isso pode ser deitado pela janela fora no altar de um ego sem limites." (14/10/2015) As consequências económicas de uma viragem do país à esquerda assusta os editorialistas. No Diário de Notícias, André Macedo afirma que "para o país, dividido e assustado, zonzo de tanta reviravolta, encarar um governo das esquerdas significa juntar nova dose de risco a uma economia onde viver já é perigoso." (13/10/2015) No Correio da Manhã, Octávio Ribeiro, o diretor, assustado com a "maioria excêntrica" considera que "se Centeno [o ministro das finanças] quiser cumprir as promessas, vai ter de aprender a dizer não e dar saudáveis murros na mesa. Não parece capaz de tal proeza." (25/11/2015)

À falta de argumentos constitucionais, os editorialistas centram-se também na tradição que manda formar Governo o partido vencedor das eleições. É o próprio Publico que o reconhece: "É certo que os preceitos constitucionais não exigem que o Primeiro-Ministro indigitado seja o líder do partido vencedor, referindo apenas que o chefe de Estado deve ter «em conta os resultados eleitorais», mas a tradição tem seguido esse caminho e deve ser mantida." (16/10/2015) O Diário de Notícias defende que deve ser Pedro Passos Coelho a formar governo, pois "quem ande na rua e oiça a voz do país real descobre facilmente que a percepção dominante" é essa. "Tudo o que saia fora desta paisagem é lido como golpada", acrescenta Nuno Saraiva, membro da direção do jornal. No Correio da Manhã, escreve-se que "o facto de Passos ganhar uma eleição ao fim de 4 anos de duríssima austeridade e, apesar disso, arriscar-se a ficar na oposição é a semente de uma mudança muito perigosa na perceção popular da democracia." (14/10/2015). No dia seguinte, no mesmo jornal António Costa é acusado de "tentar ganhar na secretaria um jogo que perdeu em campo." $(15 / 10 / 2015)$ 
Tabela 6: Os protagonistas políticos nos Editoriais

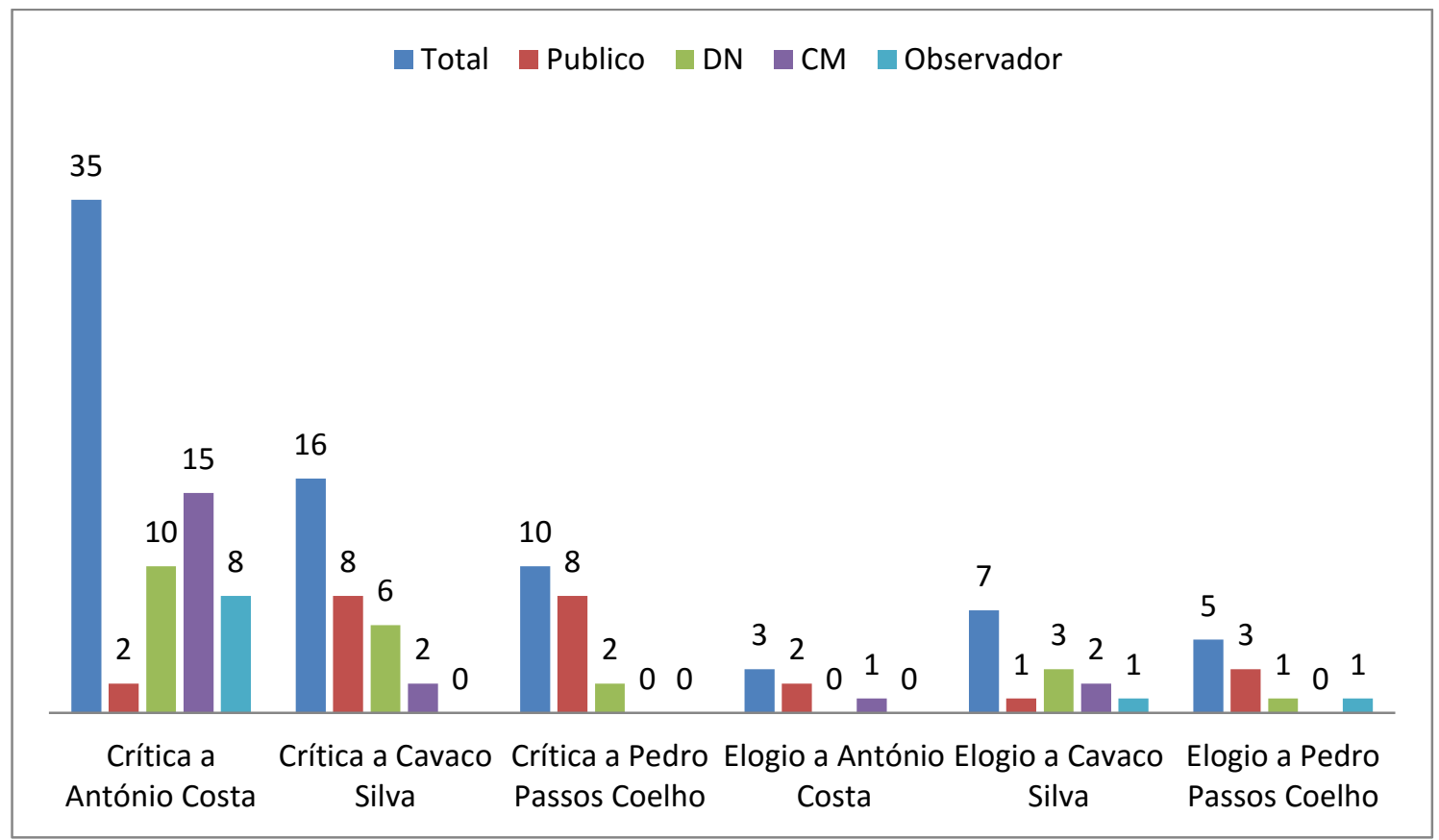

Fonte: Elaboração própria

Além do secretário-geral do PS, o alvo dos Editoriais é o Presidente da Republica. No final do seu mandato, Cavaco Silva foi violentamente criticado pela forma como atuou neste processo. O Público ataca "a indefinição do Presidente" que "só contribui para agravar, ainda mais, a situação do país." (12/11/2015). Dias mais tarde, o mesmo jornal descobre "um Cavaco desconhecido" porque "sete semanas após as eleições, o país continua em suspenso, sem ter a mínima ideia do que o Presidente da Republica tenciona fazer." (21/11/2015) Quando se aproxima uma decisão, o Publico aponta "o pesadelo de Cavaco": "o arrastar da crise política evidencia o sabor amargo de quem se despede do cargo com a consciência de que não deixa propriamente um Portugal próspero e feliz." (24/11/2015) O Diário de Notícias, por seu lado, não Ihe perdoou a mensagem que decidiu transmitir aos portugueses, duas semanas depois das eleições: "se o bem mais precioso neste momento é a estabilidade, Cavaco Silva deu-lhe ontem um forte abanão. " (23/10/2015) O silêncio, em que caiu depois, e "em que, dizem os cavacólogos, é mestre em seguir" foi depois atacado com ironia: "e o país suspenso de sua excelência o Presidente da Republica." (14/11/2015) Eduardo Dâmaso no Correio da Manhã acusa-o de "regar o fogo com gasolina (...) Podia despachar-se na indigitação de um novo Primeiro-Ministro e tirar férias." (12/11/2015)

\section{Conclusão}

Paquete de Oliveira (2017) identifica "três sensibilidades dominantes no acto de produção de informação e opinião nos media portugueses": o medo (decorrente da débil situação económica das empresas de comunicação social), a ideologia económica e a "catequização militante". Em conjunto, estes três eixos formaram nas eleições legislativas de 2015 o quadro perfeito para a " defesa acérrima do status quo" (Oliveira, 2017:472) que, em nosso entender, se prolongou no período pós eleitoral de formação do Governo. Com efeito, como demonstram os editoriais do Diário de Notícias, Público, Correio da Manhã e 
Observador durante esses dois meses, a opinião dominante seguiu no sentido de favorecer a formação de um executivo que integrasse os partidos do "arco da governação" afastando a possibilidade de uma aliança entre os partidos da esquerda, até aí arredados do poder. A elite jornalística propagou deste modo o discurso dominante próprio de "um «pensamento único», sem pistas de alternativa" (Oliveira, 2017:472), reproduzindo uma "cega atitude reverencial face aos consensos oficiais" (Arrese y Vara-Miguel, 2014:935). Esta postura detetada pelos investigadores espanhóis Ángel Arrese e Afonso Vara- Miguel ao analisarem a cobertura mediática da crise económica, julgamos também ter encontrado neste primeiro olhar sobre a imprensa portuguesa num período político tão conturbado.

Na capa dos jornais, através da titulação e do enquadramento informativo, verificámos que as negociações eram apresentadas sob o binómio Estabilidade / Instabilidade. Enquanto a primeira era associada à tradicional solução do Bloco Central + 1 (PSD + PS + CDS), a segunda era conotada com a esquerda (PS + $\mathrm{PCP}+\mathrm{BE}+\mathrm{PEV})$. Os media receavam o pior para o país com um Governo apoiado pelos partidos de esquerda, que questionavam as políticas impostas pela Troika durante a crise dos últimos anos, e foi esse cenário que veicularam para os seus leitores. O consenso mediático formado à volta da necessidade da política de austeridade imediatamente anterior contribuiu para esta visão dicotómica. Mesmo não lendo as estórias que acompanhavam os títulos no interior do jornal, uma observação da "montra" da imprensa determinava esta visão crítica e negativa face a tal desfecho, e à não prossecução de uma negociação entre os partidos do chamado "arco da governação" como sempre aconteceu até aí. O cenário de "normalidade" colapsou perante o inconformismo da elite jornalística que, confrontada com a "novidade" atuou como resistente e adversária defendendo a manutenção da tradicional lógica política, como demonstrou a teoria crítica. À semelhança do que aconteceu no Reino Unido com o líder do Partido Trabalhista, os editoriais portugueses mostram como a elite jornalística adotou o papel de "cão de ataque" (attackdog).

Confirmando a tendência do jornalismo político, as notícias da formação do Governo do PS com o apoio parlamentar dos partidos da esquerda foram enquadradas de acordo com a lógica do Jogo (Game Scheme) em detrimento das Políticas (Policy Scheme), o que no entender de vários autores contribui para a desconfiança e o cinismo com que os cidadãos veem a política (Cappella e Jamieson, 1996). Apesar de tudo, julgamos que este enquadramento é compreensível por se tratar precisamente de um momento negocial em que as várias partes envolvidas jogam tudo para ganhar terreno e salvaguardar a sua posição, numa lógica natural de vencedores e vencidos, em que a informação pode ser o trunfo maior. Se os atores gerem as palavras e as ações entre si, também têm especial cuidado na forma como o fazem com os media pois a percepção publica da negociação pode ser decisiva para o evoluir da mesma. Reconhecemos no entanto que esta seleção, ao expor de forma negativa tais movimentações dando-Ihes um caráter de anormalidade política, confirmou a imprensa como um dos atores da negociação política em curso.

\section{Bibliografia}

Aalberg, T., Strömbäck, J. and de Vreese, C.H. (2011). The framing of politics as strategy and game: A review of concepts, operationalizations and key findings, Journalism, 13(2), 162-178. DOI: $10.1177 / 1464884911427799$ 
Andrew, Blake C. (2007), Media generated Shortcuts: Do Newspaper Headlines Present Another Roadblock for Low-Information Rationality? The International Journal of Press/Politics, 12(2), 24-43, DOI:10.1177/1081180X07299795

Arrese, Ángel y Alfonso Vara-Miguel (2014). Alarma y alarmismo: medios de comunicación y crisis económica. Estudios sobre el Mensaje Periodístico, 20(2), 933-951. DOI: 10.5209/rev_ESMP.2014.v20.n2.47042

Basu, Laura, Steve Schifferes and Sophie Knowles (2018). The Media and Austerity - Comparative Perspectives. New York: Routledge

Cammaerts, B., Brooks D., Magalhães, J.C. and Jimenez-Martinez, C. Journalistic Representations of Jeremy Corbyn in the British Press: From Watchdog to Attackdog. Media@LSE. Report, http://www.Ise.ac.uk/media-and-

communications/assets/documents/research/projects/corbyn/Cobyn-Report.pdf consultado em $20 / 09 / 2018$

Cappella, J. N. and Jamieson, K.H. (1996), News Frames, Political Cynicism, and Media Cynicism. The Annals of the American Academy, 546, 71-84

Castells, M. (2003). O Poder da Identidade - A Era da Informação: Economia, Sociedade e Cultura. Lisboa: Fundação Calouste Gulbenkian.

Cook, T. E. (2006) The News Media as a Political Institution: Looking Backward and Looking Forward. Political Communication, 23(2), 159-171, DOI: $10.1080 / 10584600600629711$

Davis, A. (2007), Investigating Journalist Influences on Political Issue Agendas at Westminster. Political Communication, 24(2), 181-199. DOI:10.1080/10584600701313033

de Giorgi, E. \& Santana-Pereira, J. (2016). The 2015 Portuguese Legislative Election: Widening the Coalitional Space and Bringing the Extreme Left. South European Society and Politics, 21(4), 1-19, DOI: 10.1080/13608746.2016.1181862

Dor, D. (2003), On newspaper headlines as relevance optimizers, Journal of Pragmatics, 35, 695-721.

Doudaki, V. (2015), Legitimation Mechanisms in the Bailout Discourses, Javnost-The Public, 22(1), 1-17, DOI: $10.1080 / 13183222.2015 .1017284$

Eilders, C. (1997), The Impact of Editorial Content on the Political Agenda in Germany: Theoretical Assumptions and Open Questions Regarding a Neglected Subject in Mass Communication Research, Working paper, FS III 97-102, Berlin: WZB Berlin Social Science Center.

Entman, Robert M. (2007). Framing Bias: Media in the Distribution of Power. Journal of Communication 57(1), 163-173. DOI: 10.1111/j.1460-2466.2006.00336.x

Entman, R. M., Matthes, J. and Pellicano, L. "Nature, sources, and effects of news framing". In WahlJorgensen, K. and Hanitzsch, T. (Eds.) (2009). The Handbook of Journalism Studies. New York: Routledge.

Fernandes, J. M. (2016). The seeds for party system change? The 2015 Portuguese general election. West European Politics, 39(4), 890-900, DOI: 10.1080/01402382.2016.1150645

Fernandes, J. M. \& Carlos J. (2017). A resurgent presidency? Portuguese semi-presidentialism and the 2016 elections. South European Society and Politics, 22(1), 121-138, DOI: 10.1080/13608746.2016.1198094 
Gans, H.J. (1980), Deciding What's News - A Study of CBS Evening News, NBC Nightly News, Newsweek and Time. New York: Vintage Books Edition.

Gradim, A. (2016), Framing, o enquadramento das notícias. Lisboa: Livros Horizonte

Herman, E. S. \& Chomsky, N. (1994). Manufacturing Consent - The political economy of the Mass Media. London: Vintage

Hjarvard, S. (2008). The Mediatization of Society - A Theory of the Media as Agents of Social and Cultural Change. Nordicom Review, 29 (2), 105-134.

Jalali, C. (2007), Partidos e Democracia em Portugal 1974-2005. Lisboa: Imprensa de Ciências Sociais.

Lichter, S. R. (2017). "Theories of Media Bias". In Kenski, K. and Jamieson, K.L. (ed.). The Oxford Handbook of Political Communication. Oxford: Oxford University Press.

Lisi, M. (coord.) (2015). As eleições legislativas no Portugal democrático 1975-2015. Lisboa: Assembleia da Republica-Divisão de Edições.

Lisi, M. (2016). U-Turn: The Portuguese Radical Left from Marginality to Government Support. South European Society and Politics, 21(4), 1-21. DOI: 10.1080/13608746.2016.1225331

Marques, F. P. J., Mont'Alverne, C. and Mitozo, I.B. (2018), A empresa jornalística como ator político: Um estudo quanti-qualitativo sobre o impeachment de Dilma Roussef nos editoriais de Folha e Estadão. Observatorio (Obs*), 12(3), 224-245. DOI:10.15847/obsOBS12320181166

Matos, J. N., Baptista, C. and Subtil, F. (2017). A Crise do Jornalismo em Portugal. Lisboa: Deriva Editores. Mazzoleni, G. \& Schulz, W. (1999). "Mediatization" of Politics: A Challenge for Democracy? Political Communication, 16(3), 247-261. DOI: 10.1080/105846099198613

McCombs, M. (1997). Building Consensus: The News Media's Agenda-Setting Roles. Political Communication, 14(4). 433-443. DOI: 10.1080/105846097199236

Meyer, T. and Hinchman, L. (2002). Media Democracy-How the Media Colonize Politics. Cambridge: Polity Press.

Negrine, R. (1996). The Communication of Politics. London: Sage.

Oliveira, L. (2018). O jornalismo brasileiro como ator político. Revista Compolítica, 8(1), 147-163. DOI: 10.21878/compolitica.2018.8.1.160

Oliveira, J.M.P (2017). Comunicação e Quotidiano - Textos e Intervençoes (1983-2016). Lisboa: Tinta da China.

Paschal P. \& Silke, H. (2014). Ireland - From Neoliberal Champion to "the Eye of the Storm". Javnost - The Public, 21(4), 5-23. DOI: 10.1080/13183222.2014.11077100

Patterson, T. E. (1994). Out of Order. New York: Vintage Books.

Patterson, T. E. (1997). The News Media: An Effective Political Actor? Political Communication, 14(4), 445-455. DOI: 10.1080/105846097199245

Patterson, T. E. (2003), Tendências do jornalismo contemporâneo-Estarão as notícias leves e o jornalismo crítico a enfraquecer a Democracia? Media \& Jornalismo, 2, 19-47.

Schudson, M.(2011), The Sociology of News. New York: W.W. Norton \& Company.

Serrano, E. (2006), A dimensão política do jornalismo. Comunicação \& Cultura, 2, 63-81.

Sousa, H. \& Santos, L.A. (2014), Portugal at the eye of the storm: Crisis, Austerity and the Media. Javnost - The Public, 21(4), 47-61. DOI: 10.1080/13183222.2014.11077102 
Spörer-Wagner, D. and Marcinkowski, F. (2010). Is Talk Always Silver and Silence Golden? The Mediatisation of Political Bargaining. Javnost - The Public, 17(2), 5-26.

Stasavage, D. (2004), Open-Door or Closed-Door? Transparency in Domestic and International Bargaining. International Organization, 58, 667-703. DOI: 10.1017/S0020818304040214.

Strömbäck, J. (2008), Four Phases of Mediatization: An Analysis of the Mediatization of Politics. Press/Politics, 13(3) 228-246. DOI: 10.1177/1940161208319097

Traquina, N. (org.) (1993). Jornalismo: Questões, Teorias e «Estórias». Lisboa: Veja.

Weaver, D., McCombs, M. and Shaw, D.L. (2004). "Agenda-Setting Research: Issues, Attributes, and Influences". In Kaid, L. L. (ed.). Handbook of political communication research. London: Routledge. 